\title{
РАЗРАБОТКА И ПРЕДСТАВЛЕНИЕ КЕЙС-ПАКЕТОВ ИЗ ЛИЧНОГО ПРАКТИЧЕСКОГО ОПЫТА ПРЕПОДАВАТЕЛЕЙ ДИСЦИПЛИН КОРРЕКЦИОННОЙ И СОПУТСТВУЮЩЕЙ НАПРАВЛЕННОСТИ В СИСТЕМЕ ПОДГОТОВКИ СПЕЦИАЛИСТОВ КОРРЕКЦИОННОГО ПРОФИЛЯ
}

\section{DEVELOPMENT AND PRESENTATION \\ OF CASE PACKAGES FROM PERSONAL \\ PRACTICAL EXPERIENCE OF TEACHERS OF DISCIPLINES OF CORRECTIONAL AND RELATED ORIENTATION \\ IN THE SYSTEM OF TRAINING SPECIALISTS OF CORRECTIONAL PROFILE \\ E. Rybakova \\ R. Sultanova \\ G. Gayazova \\ A. Kutdusova}

Summary: The team of authors of the Department of Pedagogy of the Federal State Budgetary Educational Institution of Higher Education of BashSU presents the experience of updating in teaching practice the experience of specialized support of students with disabilities from various sides of the specification. The use of real situations from the personal practice of teachers as case studies of various levels of complexity, suggesting individual and collective, analytical and project resolution, allows future specialists to form a sense of presence in diagnostic and corrective, health-saving situations, to take part in the correlation of practice-oriented information available at the current level. and the scientific basis of special education, to improve the overall quality of training of university graduates, to support various forms of cooperation of young specialists, experienced practitioners, the parent community, heads of educational organizations in the system of continuous education of students of the Department of Pedagogy of Bashkir State University. The specificity of the development of case studies by the teachers of the Department of Pedagogy of the Faculty of Psychology of Bashkir State University was the comparison of the current trends in targeted correctional and developmental support of students with disabilities with the earlier experience of the authors, so that future colleagues can observe learning situations in temporal comparison, in the dynamics of the development of special didactics, and also directly observe for the formation of training cases from vivid examples of direct practice of teachers of specialized disciplines.

Keywords: students with disabilities, special education, development, case studies, health-saving educational technologies.

\author{
Рыбакова Елена Владимировна \\ старший преподаватель, ФГБОУ ВО «Башкирский \\ государственный университет» \\ evrybakova19@mail.ru
}

Султанова Роза Миниахметовна к.n.н., дочент, ФГБОУ ВО «Башкирский государственный университет»

Гаязова Гульшат Анифовна

к.м.н, дочент, ФГБОУ ВО «Башкирский государственный университет»

Кутдусова Анастасия Андреевна старший преподаватель, ФГБОУ ВО «Башкирский государственный университет»

Аннотация: Авторский коллектив кафедры педагогики ФГБоу ВО БашГу представляет опыт актуализации в преподавательской практике опыта профильного сопровождения обучающихся с ограниченными возможностями здоровья с различных сторон спецификации. Использование реальных ситуаций из личной практики преподавателей в качестве кейсовых заданий различного уровня сложности, предполагающих индивидуальное и коллективное, аналитическое и проектное разрешение, позволяет сформировать у будущих специалистов ощущение присутствия в диагностических и коррекционных, здоровьесберегающих ситуациях, принять доступное на текущем уровне участие в соотнесении практикоориентированной информации и научного базиса специального образования, повысить в целом качество подготовки выпускников университета, поддерживать различные формы сотрудничества молодых специалистов, опытных практиков, родительского сообщества, руководителей образовательных организаций в системе непрерывного образования обучающихся кафедры педагогики БашГУ. Спецификой разработки кейсовых заданий преподавателями кафедры педагогики факультета психологии БашГУ стало сопоставление текущих трендов адресного коррекционно-развивающего сопровождения обучающихся с ОВ3 с более ранним опытом авторов, так что будущие коллеги могут наблюдать обучающие ситуации в темпоральном сравнении, в динамике развития специальной дидактики, а также непосредственно наблюдать за формированием обучающих кейсов из ярких примеров непосредственной практики преподавателей профильных дисциплин.

Ключевые слова: обучающиеся с ограниченными возможностями здоровья, специальное образование, развитие, кейсовые задания, здоровьесберегающие образовательные технологии. 
K артина современного детства, нозологической ситуации и, соответственно, особых образовательных и жизненных потребностей, структуры и состава образовательных условий стремительно меняется, зачастую значительно, с институциональным преобразованием среды, системы обучения, социально-личностного компонента общей и специальной дидактики.

Эти сложность и динамизм востребуют от высшего образовательного звена в системе подготовки будущих специалистов как совершенствования и адресной актуализации уже имеющихся, классических основ образования, так и готовности осмысливать, изучать, прогнозировать значимые изменения в образовательном пространстве, разрабатывать, апробировать и эффективно применять современные средства обучения, перспективно значимые модели образования, с соблюдением условий безопасности, единства и жизнеспособности образовательного пространства.

Классические принципиальные, организационные и содержательные основы образовательных систем являются золотым фондом отечественной и международной школы всех уровней, как и давние традиции преподавания педагогических дисциплин в классическом вузе, особенности заочного преподавания, а также освоение компетенций коррекционно-развивающей направленности имеют славную историю и литературный базис.

Вместе с тем закономерное преобразование современной парадигмы образования, внедрение ФГОС, равно как и задаваемые государственными стандартами принципы демократизация образовательного пространства, проблемы и ресурсные аспекты продвижения инклюзивного образования, иных форматов социально-образовательного сопровождения, необходимость обеспечивать условия компенсации, сверхкомпенсации нарушений в развитии обучающихся с ограниченными возможностями здоровья (далее - ОВ3, что предполагает стойкое значимое для образовательной деятельности детей нарушение функций, связанное с особенностями состояния их здоровья) - таков спектр проблем, решаемых современным педагогическим и родительским сообществом (1), широкой общественностью, государственными структурами.

Наши будущие коллеги в данном контексте должны и имеют право представить наглядно, образно, внятно и вместе с тем в системе философского, системного психолого-педагогического знания будущее поле своей профессиональной деятельности в движении, саморазвитии, взаимодействии факторов и смыслов $(2,3)$.

Соответственно, одним из наиболее эффективных подходов для решения данного проблемного кластера является сочетание высокой научной достоверно- сти подготовки и классической университетской базы преподавания профессорско-педагогического состава с аналитико-исследовательским и практикоориентированным сотрудничеством всех участников высшей ступени образования будущих специалистов коррекционного профиля (4. 5) с опорой на непосредственный успешный, комплексный, подвижный и развивающийся опыт сопровождения обучающихся с ограниченными возможностями здоровья $(6,7)$.

В соответствии с профилем организации системы адресного сопровождения обучающихся различных нозологических групп целесообразно предоставить студентам возможность в ходе освоения общих и специфических профессиональных компетенций получать представление о классических основах изучаемых дисциплин, их исторических предпосылках, динамике текущего развития, перспективах дальнейшего осуществления внутренних и межпредметных процессов, артефактной составляющей осваиваемых научных, практических областей получаемого образования - в сопоставлении, подкреплении, столкновении с передаваемого преподавателями личного опыта медицинской, психолого-педагогической, социальной диагностики, коррекционно-развивающего праксиса в контексте сотрудничества со специалистами общего профиля и иной спецификации (7).

Высокая ответственность, неоднозначность, сложность и разноплановость системы адресной поддержки обучающихся с ОВ3, детей-инвалидов $(8,9)$ рассматривается нашими преподавателями в ходе образовательных мероприятий с повышенным проектным содержанием: авторы исследования, а затем и сами студенты, соблюдают принцип первенства студентов в предоставлении им возможности высказать своё мнение, предположения, интерпретацию фактов (10), обобщение наблюдений (11), прогнозирование учебной ситуации, сформулировать заключение, рекомендации, решение по комплектованию обучающихся с ОВ3, детей-инвалидов для получения ими максимально благоприятных, эффективных условий образования, повышения уровня удовлетворённости обучающимися, их семьями, общественностью получаемыми образовательными услугами и достигаемыми результатами.

Самые сложные понятия, в преломлении теории и непосредственного опыта преподавателя, с интеграцией аспектов психолого-педагогических, медицинских взглядов через обучающие внутренние консилиумы, как дистанцированные, так и приближенные к текущему образовательному сопровождению обучающихся $(12,13)$, современный опыт реализации инклюзивного обучения, универсальной среды пополняют собой кейсы, помогают студентам самостоятельно сформулировать рациональное, современное определение каждому факту, 
каждой тенденции и процессу, более адресно и целенаправленно отбирать значимые ссылки в растущих просторах информационного пространства.

По-прежнему недостаёт в арсенале специальной педагогики практикоориентированного базиса не только сверхкомпенсаторного (когда ребёнок с ОВ3 имеет возможность опережающего развития в тех функциональных и компетентностных областях (14), в которых он наиболее уязвим, испытывает затруднения вследствие дефицитарности функции) характера, но, в целом, даже компенсаторные области специальной дидактики ( то есть ресурсы и технологии преодоления нарушенных функциональных регистров за счёт актуализации более сохранных) не в полной мере освещены отечественной и зарубежной литературой, а также периодически нарастает необходимость соотнести то разнесённые, то сближающиеся процессы параллельного развития науки и практики различных территориальных, государственных субъектов.

Отдельным важным звеном в данном праксисе является исследовательский, проектный ресурс преподавателей и наших коллег, показывая будущим коллегам непосредственно, насколько существенным может быть запрос общества, ситуации, прогнозируемых обстоятельств на обновление науки, инклюзивной, коррекционно-образовательной среды $(15,16)$, разработки новых решений, методов, условий адресного сопровождения для преодоления категориальных и конкретных, частных проблем детского развития, самопозиционирования и самоадвокации обучающихся с ОВ3, обучающихся инвалидов.

Современные исследования и достижения практиков также закономерно становятся основанием для разработки кейсовых и иных проблемных заданий, для предоставления студентам выявить и презентовать их скрытые возможности, вербальный и аналитический, проектный потенциал $(17,18)$.

Значительным ресурсом формирования и совершенствования профессиональных и личностных компетенций будущих специалистов $(19,20)$ является база аналогий, примеров и задач из смежных областей знания и опыта, позволяющих на неспецифических предметных ситуациях разносторонне осветить самые сложные, неоднозначные, парадоксальные компоненты специального образования. Здесь разноплановый опыт и представ- ления преподавателей также становятся действенным ресурсом повышения качества, уровня, жизненности и устойчивости образования.

При проведение совместной проектной деятельности преподавателей и студентов такой опыт приобретает особенно актуализирующую, креативно значимую роль. Так, например, осуществляя проект социальной направленности по выявлению субъектных ресурсов родственников, социальных работников, медицинских специалистов, сопровождающих пожилых граждан в беспомощном состоянии, студенты рассматривают аспекты межведомственного сотрудничества применительно к иным категориям сопровождаемых лиц (21).

Таким образом, применение кейсовых заданий, основанных на сочетании собственного опыта преподавателей, распределенного во времени, с практикоориентированной деятельностью обучающих и обучающихся, с опытом работающих студентов, как в области общего, так и коррекционно-развивающего образования, представляет собой систему сотрудничества всех участников высшей ступени обучения будущих специалистов коррекционного профиля.

Существенно, что обучающиеся в вузе в таком формате получают возможность наблюдать текущий практический опыт преподавателей в темпоральной трансполяции эмпирики и анализа, что не только позволяет студентам понимать, чувствовать, осмысливать динамику развития собственно системы специального образования и соответствующего высшего специального образования - но и формировать готовность к пониманию наметившихся тенденций преобразования пространства общей и коррекционной дидактики, а также более глобальные, более общие процессы, что важно студентам в гражданственном, личностном плане.

Проектная актуализация возможностей и личности обучающихся в комплексном кейсовом обеспечении сотрудничества всех участников образовательного пространства обеспечивает, между тем, также и благоприятное психоэмоциональное самочувствие, создавая преимущество личностно и деятельностно ориентированным образовательным технологиям в современном вузе, что существенно даже для соматического здоровья обучающихся и обучающих, а также предупреждает возможные в будущем эмоциональное выгорание и профессиональную деформацию.

\section{ЛИТЕРАТУРА}

1. Рыбакова Е.В., Султанова Р.М, Гаязова Г.А. Moduling of contact with of children with asd and manifestations of negativism didactic. - Maтериалы VII международной научно-практической конференции "Образование: традиции и инновации", Прага, World Press, 2015;

2. Султанова Р.М., Гаязова Г.А., Рыбакова Е.В. Современный личностно-правовой аспект адресного сопровождения детей с РАС. - Итоговый сборник мате- 
риалов Второго Съезда дефектологов, Москва, 2017;

3. Султанова Р.М., Гаязова Г.А., Рыбакова Е.В. Изучение и развитие ресурсов сотрудничества взрослых, сопровождающих ребёнка с РАС. - Итоговый сборник материалов Второго Съезда дефектологов, Москва, 2017;

4. Рыбакова Е.В., Султанова Р.М., Гаязова Г.А. Личное время, личная территория ребёнка с ОВЗ - основные составляющие его социально-деятельностного определения в образовательном пространстве. - Проблемы социализации и индивидуализации личности в образовательном пространстве. - Материалы международной научно-практической конференции, Белгород, 2018, стр. 291;

5. Рыбаков, Д.Г., Султанова, Р.М., Гаязова, Г.А. ИТ-самоучители в жизни детей и взрослых с ограниченными возможностями здоровья [электронный текст] // Культура и технологии. 2019. Том 4. Вып. 2. С. 77-82. URL: http://cat.ifmo.ru/ru/2019/v4-i2/176;

6. Рыбаков Д.Г., Султанова Р.М., Гаязова Г.А. Избирательное социальное дистанцирование, - Культура и технологии \Электронный мультимедийный журнал, т. 3, выпуск 1-2, 2018;

7. Рыбакова Е.В., Султанова Р.М., Гаязова Г.А., Рыбаков Д.Г., Нурыева У.И. Исследование и актуализация проектного ресурса развития ребёнка. - Национальная ассоциация учёных (НАУ): Ежемесячный научный журнал № 64/ 2021,1часть. -ISSN 2413-5291, c.27-31, D0I: 10.31618/NAS.2413-5291.2021.1.64.

8. Гаязова Г.А., Рыбаков Д.Г., Рыбакова Е.В., Султанова Р.М. Проектный ресурс исторических искажений в игровом пространстве Культура и технологии. 2020. T. 5. № 1. С. 37-43;

9. Султанова Р.М., Гаязова Г.А., Рыбакова Е.В. Интерактивный ресурс для освоения реалий окружающего мира ребёнком с ограниченными возможностями здоровья В сборнике: Педагогическая наука и педагогическое образование в классическом вузе. Материалы ежегодной Международной научно-практической конференции. Ответственный редактор А.С. Гаязов. 2019. С. 237-245.

10. Султанова Р.М., Гаязова Г.А., Рыбакова Е.В. Актуализация личного и профессионального опыта, продуктивных возможностей студентов в качестве ресурсного компонента высшего образования. В сборнике: Педагогическая наука и педагогическое образование в классическом вузе. материалы ежегодной Международной научно-практической конференции. Гаязов А.С., отв. ред.. 2018. С. 120-125;

11. Рыбакова Е.В., Султанова Р.М., Гаязова Г.А. Организация блока вариативных стимульных материалов и пособий для обеспечения избирательной познавательной активности детей с РАС В сборнике: Деятельность ПМПК в современных условиях. Ключевые ориентиры. сборник материалов Всероссийской конференции. Российский университет дружбы народов. 2018. С. 149-154.

12. Рыбакова Е.В., Султанова Р.М., Гаязова Г.А., Рыбаков Д.Г. Воспитание конфликтности или включение в гармонию актуальности В сборнике: Солидарность и конфликты в современном обществе. материалы научной конференции. 2018. С. 308-309.

13. Султанова Р.М., Гаязова Г.А., Рыбакова Е.В. Интерсубъектный компонент в системе сопровождения ребёнка С РАС В сборнике: Теоретические и прикладные проблемы психологического здоровья и экологии человека. Сборник научных статей Международной научно-практической конференции. отв. редактор Р.Р. Халфина. 2017. С. $62-65$.

14. Рыбакова Е.В., Султанова Р.М., Гаязова Г.А. Формирование педагогических компетенций социально-деятельностной направленности в системе заочного обучения. Проблемное обучение в современном мире: VII Международные Махмутовские чтения (Елабуга, 5-6 апреля 2018 г.): сборник статей / науч. ред. Д.М.Шакирова. - Казань: Отечество, 2018. - 384 с. ISBN 978-5-906894-34-2, стр.124-129.

15. Рыбакова Е.В. Изучение и поддержка готовности обучающихся к проектным, креативным, индивидуально приоритетным формам сотрудничества с преподавателями с применением разработанных Л.С. Выготским принципов и подходов Актуальные проблемы культурно-исторической психологии: материалы Первого международного симпозиума по культурно-исторической психологии (Новосибирск, 17-19 ноября 2020 г.) / сост. Т.Э. Сизикова, Н.Н. Попова, О.А. Дураченко. - Новосибирск : Изд-во НГПУ, 2020. - 508 с. - Текст: непосредственный. ISBN 978-5-00104-601-1, стр. $342-328$.

16. Гаязова Г.А., Гурова Е.В., Кузнецова И.В., Кутдусова А.А., Султанова Р.М., Рыбакова Е.В., Фахретдинова Г.Ф. Интерактивный ресурс для освоения реалий окружающего мира ребёнком с ограниченными возможностями здоровья // Современная наука: Актуальные проблемы теории и практики. Серия «Гуманитарные науки» - №11/2 2020 DOI 10.37882/2223-2982.2020.11-2.06 URL: http://www.nauteh-journal.ru/index.php/2/2020/\%E2\%84\%9611/2/7da8ea 2a-0abe-4154-91f1-0ab02401e439 Дата обращения 09.01.2021;

17. Рыбакова Е.В., Султанова Р.М., Гаязова Г.А. Индивидуализированный педагогический мониторинг как обеспечение условий эффективного неврологического сопровождения детей с ограниченными возможностями здоровья. - Дефектология в свете современных нейронаук: теоретические и практические аспекты: Сб. материалов I Международной научной конференции, 23-24 апреля 2021 г. / Под общ. ред. Т. Г. Визель. М.: Когито-Центр - Московский институт психоанализа, 2021. - 825 с. ISBN 978-5-89353-624-9, стр. 761-771.

18. Рыбакова Е.В., Султанова Р.М., Гаязова Г.А., Рыбаков Д.Г. Развитие инклюзивного образования на текущем этапе. Региональный опыт. Научные исследования и инновации. Сборник статей VI Международной научно-практической конференции: сборник статей, Гэлектронное издание сетевого распространения] / Под ред. Н.В. Емельянова. - М.: “КДУ”, “Добросвет”, 2021. - 136 с. - URL: https://bookonlime.ru/node/39417 - doi: $10.31453 /$ kdu.ru.978-5-7913-1173-3-2021-136.ISBN 978-5-7913-1173-3;

19. Султанова Р.М., Гаязова Г.А., Рыбакова Е.В., Нурыева У.И. «Исследование и актуализация проектного ресурса развития ребёнка». - «Национальная ассоциация учёных (НАУ)- Ежемесячный научный журнал (№ 64/ 2021,1часть. -ISSN 2413-5291), D0I: https://doi.org/10.31618/NAS.2413-5291.2021.1.64;

20. Рыбакова Е.В., Султанова Р.М., Гаязова Г.А. Событийная дидактика в специальном образовании. - Сборник II Всероссийской научно-методической конференции «Всероссийский педагогический форум», состоявшейся 15 ноября 2020 г. В г. Петрозаводске ISBN 978-5-00174-039-1 D0I 10.46916/20112020-4978-5-00174-039-1

21. Рыбакова Е.В., Султанова Р.М., Гаязова Г.А. Проектное изучение субъектных аспектов адресной поддержки пищевого поведения пожилых граждан в формате сотрудничества родственного окружения, специалистов медицинского и социального сопровождения // Современная наука: актуальные проблемы теории и практики. Серия: Гуманитарные науки. -2021. -№04/2. -С. 120-125 D0I 10.37882/2223-2982.2021.04-2.30

(с) Рыбакова Елена Владимировна (evrybakova19@mail.ru), Султанова Роза Миниахметовна, Гаязова Гульшат Анифовна, Кутдусова Анастасия Андреевна. Журнал «Современная наука: актуальные проблемы теории и практики» 